RESEÑA

\title{
Las disciplinas escolares y sus libros
}

\author{
School disciplines and their books
}

\section{Karla Liebed Solis García ${ }^{1}$}

Carlos Inclán Fuentes ${ }^{2}$

\begin{abstract}
Resumen
En este texto se ofrece una reseña al libro Las disciplinas escolares y sus libros coordinado por Luz Elena Galván Lafarga y Lucía Martínez Moctezuma. La obra representa una aportación al estudio del desarrollo de las disciplinas escolares a partir del análisis de contenido de libros o textos escolares utilizados, principalmente, en la enseñanza de la educación básica en México en un periodo que abarca casi dos siglos. Los colaboradores analizan distintas temáticas que se engloban en tres secciones: ciudadanía y enseñanza de la historia y civismo, la enseñanza de las llamadas ciencias duras y finalmente dos estudios sobre la forma de enseñar las habilidades de lectoescritura.
\end{abstract}

\section{Palabras clave: educación, historiografía, disciplinas, libros escolares}

\begin{abstract}
The book Las disciplinas escolares y sus libros compilated by Luz Elena Galván Lafarga and Lucía Martínez Moctezuma is an important contribution to the study of school subjects and its development in Mexico during the last two centuries. The most important aspect of the articles of this book is the analysis of content of different books and school texts, which were used to teach in the formative levels of the educational system. The book is divided in three parts: one dedicated to the teach of history and civic values, a second one about the natural sciences and finally one for the teach of basic skills of reading and writing.
\end{abstract}

\section{Keywords: education, historiography, disciplines, school books}

\footnotetext{
${ }^{1}$ Universidad Pedagógica Nacional, México. Correo electrónico: liebedsolisl@gmail.com

2 El Colegio de México, México. Correo electrónico: cinclan@colmex.mx
} 


\section{Reseña del libro: Las disciplinas escolares y sus libros}

En las últimas décadas el interés por la historia de la educación y en particular, por el estudio de los libros de texto como "objetos complejos" han adquirido una renovada importancia, con enfoques que deparan tanto en autores como en lectores, y que abren la definición sobre el libro de texto para abarcar también a folletos, revistas, periódicos y manuales orientados a los procesos de enseñanza y a la formación de habilidades como la capacidad de lectura, la escritura y la enseñanza curricular de diversas disciplinas del saber, de la historia a la geometría, de la geografía a las "lecciones de cosas" y del civismo a la higiene.

Dentro de ese campo de estudio de la historia de los libros de texto se enmarca el trabajo coordinado por las historiadoras Luz Elena Galván Lafarga y Lucía Martínez Moctezuma, quienes en el marco del seminario "Libros escolares mexicanos, siglos xix y xx" con sede en el Centro de Investigaciones y Estudios Superiores en Antropología Social (CIESAS) lograron establecer un equipo multidisciplinario e internacional de académicos, entre pedagogos e historiadores de México, España, Argentina y Brasil interesados en la historia de la educación, la enseñanza de la historia, la formación de ciudadanía y su vínculo con la creación de una historia patria, la enseñanza de disciplinas curriculares como las matemáticas, el dibujo, la física y la economía doméstica y finalmente los procesos de lecto-escritura.

Las coordinadoras han tomado en cuenta la producción académica de los últimos veinte años, desde los trabajos pioneros de Josefina Vázquez, las investigaciones sobre la infancia lectora, la atención que se dio a la enseñanza de la historia como vehículo para la "nacionalización" a la población o el fomento de las habilidades de lectura para garantizar el proceso de construcción e integración nacional entorno a una lengua. Y no menos importante la adaptación de modelos de libros de lectura, especialmente los provenientes de Francia, lo que apunta a las influencias internacionales de los enfoques y modelos pedagógicos adoptados en el diseño de los textos, así como en los métodos de enseñanza.

El libro publicado en el año 2010 es una compilación de 14 artículos, divididos en tres secciones que se centran en el caso mexicano y abarcan una temporalidad amplia de casi dos siglos, siendo el hilo conductor el análisis de contenido de los libros de texto para "desentrañar el desarrollo de las disciplinas escolares desde mediados del siglo XVIII hasta el XX" (Galván y Martínez, 2010, pág. 15), es decir, las preguntas guías de los artículos giran en torno a cómo se construyeron e introdujeron los conocimientos en el libro de texto y al papel de los educadores encargados de "formar a varias generaciones de mexicanos". Cabe hacer la aclaración de que la mayor parte de los textos están referidos a la educación básica y la fuente de todos los estudios son los textos escolares. 
La primera parte está dedicada a la formación de ciudadanía a partir de la enseñanza de la historia en seis capítulos que abarcan el civismo, el nacionalismo y la ciudadanía, la enseñanza del derecho, la historia patria, la enseñanza de la historia y la conformación del discurso de la llamada historia oficial. La segunda parte compete a las denominadas ciencias duras: las matemáticas, las ciencias naturales, la economía doméstica, la geografía y la física. Finalmente, el tercer apartado se enfoca a los procesos de enseñanza de lectoescritura y los libros de lectura empleados en la educación básica.

Al respecto habría que notar cierto desbalance entre las secciones y un énfasis especial en el caso de la historia. La razón de ello se debe, en palabras de las compiladoras al carácter "disperso y limitado" de las fuentes de información. En ese sentido, se menciona que sólo la Biblioteca Gregorio Torres Quintero tiene un fondo especializado en libros de texto, pero con un servicio irregular. Por lo mismo, el propósito de los autores fue "seleccionar un conjunto de libros de texto y escolares para [acercarse] a su contenido y difusión". El objeto de estudio es "el libro escolar y libro de texto" en distintas disciplinas cuya finalidad era dotar de conocimientos útiles al "nuevo" ciudadano que la "nación mexicana" requería desde el siglo XIX, entre las que se incluían habilidades centradas en la lectura, escritura y la aritmética.

En su artículo Márquez Carrillo señala que la formación escolar entre finales de la colonia y las primeras décadas del México independiente se encaminó a la construcción de una ideología acorde a los estándares y características del Estado-nación mexicano. Los medios idóneos para alcanzar dicho objetivo fueron a través de la circulación de manuales de urbanidad que aseguraban la reconversión de ciertas actitudes y valores que para las autoridades y grupos sociales de élite debían reforzar la participación política y los deberes cívicos como la obediencia al Estado. Los contenidos de dichos manuales se caracterizaron por estrategias psicológicas y conductuales que posibilitaran ese cambio, de súbdito a ciudadano. Márquez Carrillo muestra un análisis general sobre los procesos de culturización en valores. Cabe señalar que la postura de la autora depara en una crítica del proceso de selección y exclusión de contenidos escolares y la imposición de preceptos para mantener el orden social.

En la línea del papel de los sistemas educativos en la construcción del Estado-nación la enseñanza de valores cívicos tuvo una importancia central. En ese sentido, Meníndez Martínez señala como el posicionamiento de una disciplina como el civismo tuvo un posicionamiento importante desde el porfiriato. De acuerdo con el contexto nacional del país se requería contenido escolar sobre la formación de ciudadanos con un sentido nacional y patriótico, también se necesitaba educar a la población para contar con mano de obra calificada que pudiese incorporarse a la creciente planta industrial y a los planes de modernización social. En palabras de la autora, "la élite educativa que rodeaba a Porfirio Díaz buscaba generar nuevos enfoques educativos con el propósito de establecer una educación vinculada con el proceso de industrialización que se estaba imponiendo en el mundo, además 
de que intentaba formar nuevas generaciones de ciudadanos trabajadores, sanos y disciplinados" (Meníndez, 2010, p. 52).

En el proceso de modernización del Estado también jugó un papel central la conformación de un marco legal, un orden constitucional que tratara de organizar la caótica situación del México del siglo XIX. En ese sentido, Galindo Peláez analiza los Ilamados "manuales de sala" que se utilizaron para enseñar derecho en el nivel de educación secundaria durante la primera mitad del siglo XIX. Galindo Peláez señala los intercambios y circulación de saberes en el sentido de que dichos manuales tuvieron su origen en 1803 en las obras del jurista Juan Sala, profesor de derecho romano en la Universidad de Valencia, autor de textos dirigidos a la enseñanza del derecho, regidos por un modelo de enseñanza que privilegiaba la memorización de contenidos. El Manual de Sala fue un texto utilizado ampliamente en las instituciones formadoras de abogados en México, que después tendrían un papel protagónico en la construcción de la nueva nación.

Además de ciudadanía y un marco legal, la nación emergente requería de una identidad nacional forjada en el relato de un pasado común. García Gutiérrez señala que ese relato de la historia tiene una cercana relación con las élites gobernantes y es en algún sentido, una visión de los vencedores. Un aspecto que queda demostrado con una visión de la historia patria, en la que destaca el papel de los liberales, que luego de derrotar a sus contrapartes conservadoras, llenaron los libros de historia con una visión histórica favorable a la perspectiva de los liberales y de su triunfo sobre sus adversarios políticos. Por otra parte, la autora resalta que, a partir de la vida independiente, el método pedagógico lancasteriano se incorporó en México y en América Latina, dicho método se basó en el diseño de preguntas graduadas y sistemáticas que permitieran a los estudiantes desarrollar autodidaxia.

En su colaboración Galván Lafarga analiza el uso de la pintura laica en los textos de historia para la construcción de una narrativa de la nación y la mexicanidad, es decir, es un estudio sobre la construcción del nacionalismo desde las artes, con una finalidad clara para la autora, ya que señala: "la historia deja de ser la de un individuo para convertirse en la historia de la nación" (Galván, 2010, p. 138). Galván Lafarga analiza los cambios y las continuidades en el uso de la pintura en textos escolares entre 1867 y 1940. Asimismo, Galván Lafarga expone que la enseñanza de la historia de manera oficial comenzó en 1867 en las escuelas del país, la asignatura se llamó "Rudimentos de historia y geografía especialmente de México". Dicha asignatura, desde la óptica de la autora rompió la brecha entre los conocimientos transmitidos que giraban en torno a pilares educativos como la lectura, la escritura o la aritmética, inaugurando con ello, la expansión de la enseñanza de la historia nacional y universal.

Por su parte, Mendoza Ramírez a partir del análisis de la estructura textual de cuatro autores señalan cómo las formas narrativas construyeron una historia oficial para fomentar 
el espíritu cívico. En este sentido, la autora muestra la importancia que el Estado confirió a la enseñanza de la historia como medio para lograr la unidad de la nación. Mendoza Ramírez expone el proceso de construcción de la llamada "historia oficial" que se plasmó como contenido en los libros de texto gratuitos. En ese sentido, se señala que la "construcción" de esa historia oficial para los libros de texto tuvo lugar en el marco de la desintegración del positivismo y el surgimiento de nuevas corrientes historiográficas, como el marxismo y el historicismo, entre 1934 y 1959 (Mendoza, 2010, p. 143).

En el periodo comprendido en el estudio de Mendoza Ramírez el contenido de los libros de texto de historia entró en polémica, lo que dio lugar a diversas discusiones respecto a la unificación de las versiones de la historia en los libros de texto oficiales. No fue sino hasta que se reformó el artículo $3^{\circ}$ de la constitución, en que se suprimió la llamada educación socialista, que el Estado implementó un proyecto para transmitir la ideología oficial sobre la unidad nacional. De tal forma que, el trabajo colaborativo entre el Estado e historiadores de renombre cimentó la enseñanza de este tipo de historia.

La segunda parte del libro coordinado por Galván Lafarga y Martínez Moctezuma abre con un estudio de García Alcaraz sobre la producción, significado, cambios y continuidad de las prácticas de enseñanza de la aritmética. Para la autora, las matemáticas son consideradas como aquel conocimiento que posibilita la comprensión de múltiples tipos de fenómenos. En su artículo García Alcaraz se centra en el análisis de la producción de los libros de aritmética utilizados en la enseñanza básica y desglosa el número de libros que se utilizaban por materia en una base de datos que presenta información novedosa entre la que incluye datos sobre la diversidad de autores, títulos y casas editoriales. Dicha diversidad responde en opinión de la autora al hecho de que "la aritmética y la geometría fueron las disciplinas que tuvieron una mayor difusión en los niveles elementales de instrucción" (García, 2010, p. 168).

Por su parte, en su aportación Martínez Moctezuma sobre la difusión de las Ilamadas "lecciones de cosas" hace una exploración del tema en relación con la expansión de la educación para las clases populares. Lo anterior permite al autor enfatizar el sentido utilitario de este tipo de contenido educativo, es decir, la enseñanza se asume como la transmisión de conocimientos que ayuden a la solución de problemas sociales, por ejemplo, en el caso de la higiene o el problema del alcoholismo. La propuesta del escritor parte de su concepción de que durante el siglo XX el código escolar tenía el objetivo de fortalecer el cuerpo y mente de los niños, y en ese sentido, hacerlos perceptivos de su entorno natural. Por lo que el autor señala que "La orientación práctica de los conocimientos científicos estuvo relacionada con la solución de algunos problemas sociales de la época".

En el periodo de estudio de Martínez Moctezuma, 1889-1921, las resoluciones de los congresos Higiénico Pedagógico (1882) y de Instrucción Pública (1889-1890) fueron los pilares para la modernización de la escuela mexicana. Se dio prioridad al aprendizaje de la 
lectura pues fue considerada como el medio fundamental para la adquisición de conocimientos. Por lo tanto, los contenidos de los libros se diseñaron de acuerdo con el grado de desarrollo intelectual de los niños.

Otro aspecto por destacar es la influencia francesa en el programa de "lecciones cosas", puesto que los modelos para la modernización de los sistemas educativos tenían un origen europeo. Por lo que la admiración porfirista por lo francés reforzó ese sentido de adaptación de modelos considerados modernos y que cubrían dos metas principales: "asegurar la reproducción de valores de las nuevas clases sociales en ascenso e ilustrar a la mayor parte de la población de acuerdo con las transformaciones económicas que se estaban produciendo en el mundo occidental" (Martínez, 2010, p. 188). Habría que señalar, que la autora presenta un detallado análisis de las casas editoriales más prestigiosas de la época, a la vez que aporta datos sobre los costos de los libros y de los escritores de las "lecciones de cosas", que pueden servir de base para una consideración futura sobre la circulación y difusión de los textos.

El artículo de Moreno Gutiérrez sobre la educación de los órganos de los sentidos gira entorno a la introducción del dibujo como una disciplina cuya "importancia pedagógica" radica en su papel de "fundamento de la formación integral de los niños desde los principios de la enseñanza objetiva”. En ese sentido, el desarrollo de la sensibilidad del individuo tiene dos vertientes: la educación estética y la educación artística, que son enfocados hacia un análisis de los principios pedagógicos de la enseñanza objetiva. De acuerdo con la autora: "con base en este nuevo discurso - la nueva tendencia pedagógica (la enseñanza objetiva) las clases de dibujo se incorporaron a los programas escolares de instrucción elemental y cambiaron su sentido recreativo a un sentido educativo" (Moreno, 2010, p. 218).

La base del estudio de Moreno Gutiérrez es la Guía para profesores y manual para los alumnos en el dibujo, publicado en 1898, y cuya autoría es de Lorenzo Aduna. Para conocer cómo se pretendió desarrollar la sensibilidad en los estudiantes, Moreno identificó dos dimensiones: "Por un lado, la perspectiva estética que centra su análisis en el desarrollo de la capacidad de apreciación de lo bello y la sensibilidad creativa; por el otro, la educación artística, cuya finalidad es analizar las prácticas y los ejercicios para educar los órganos de los sentidos" (Moreno, 2010, p. 215). A través de ambas dimensiones, la autora explica la importancia y la finalidad formativa de la enseñanza del dibujo. Asimismo, integra las definiciones y argumentos de pedagogos como Johann Heinrich Pestalozzi, que apoyaron la enseñanza del dibujo, las artes, etcétera.

En sus orígenes, los llamados cursos de economía doméstica estaban orientados hacia las mujeres, que eran tomadas en cuenta en tanto sus roles sociales estancos de hijas, esposas y madres y por lo mismo adscritas al ámbito del hogar. Por consiguiente, la enseñanza de economía doméstica tenía un claro sentido práctico más que teórico, pues su finalidad era el de ayudar a las instruidas a ser "útiles" en su medio social y productivo y de dicha forma 
mejorar la economía de su núcleo familiar. Hurtado Tomás hace un estudio de la enseñanza de la economía doméstica en las escuelas primarias entre 1889 y 1910. El contenido de los libros de economía doméstica buscó transmitir conocimientos para desarrollar la conciencia y las habilidades, que, en sus futuros roles de esposas, amas de casa y madres, las mujeres habrían de desempeñar para el bienestar de sus familias.

Un aspecto que destacar de la literatura de economía doméstica era que la mayoría de las autoras eran mujeres con formación normalista. Lo anterior es de suma importancia ya que uno de los objetivos de Hurtado Tomás es rastrear el origen en "la esencia europea" y "la racionalidad económica" de los libros de texto de economía doméstica, pero aún más importante es rescatar el "papel de la mujer en un espacio privado, pues tanto su trayectoria como sus innovaciones pedagógicas dentro de la cultura escolar han pasado inadvertidas y han sido poco estudiadas por los investigadores mexicanos" (Hurtado, 2010, p. 231).

En otro sentido, se dirige el estudio de Aguirre Lora sobre la adaptación de los contenidos del estudio de la geografía a la educación pública. La autora señala que en sus inicios el conocimiento geográfico era un saber de las élites, por su carácter estratégico, ya que comprendía el estudio del territorio nacional para su explotación y defensa. De ese sentido, que podría denominarse geopolítico, se transitó a uno popular cuya finalidad era incentivar el orgullo nacional.

Aguirre Lora analiza los manuales escolares para la enseñanza de la geografía en la escuela primaria entre los años 1825 y 1898. Dicha enseñanza corrió de manera paralela a la de la historia puesto que ambas impulsaron un proceso doble, el desarrollo y defensa de la nación y el de la formación de ciudadanos. La autora señala: "Si bien la geografía como tal tuvo necesidad de ser transmitida como un campo de conocimientos imprescindibles para la vida social, su expresión como saber académico asume distintos propósitos, de acuerdo con el nivel o la institución de que se trate" (Aguirre, 2010, p. 276).

De cambios y reconversiones en los tipos de saberes habla el texto de Lazarín Miranda sobre las transformaciones en la enseñanza de la física, de su paso de la llamada física clásica a la moderna, es decir, de aquella dedicada a la enseñanza de la mecánica y de la óptica a una enfocada a la comprensión de fenómenos como el electromagnetismo, la cuántica y la radiación, entre muchos otros.

Lazarín Miranda basa su estudio en el análisis de manuales y libros de educación media en México entre 1853 y 1975, pero también incluye en su análisis un libro de educación secundaria editado en 1969. Por la temporalidad que trabaja el autor, su aportación representa un bosquejo general de un campo de estudio poco explorado y que resulta importante de estudiar porque, como refiere Lazarín Miranda, desde sus inicios la enseñanza de la física estuvo estrechamente relacionada con actividades económicas fundamentales, como en el caso de la explotación de las minas en la época colonial (Lazarín, 2010, p. 280). 
La tercera parte del libro es la más corta de la compilación y comprende solo dos aportaciones dedicadas a la enseñanza de la lectura y la escritura y en las que destacan el análisis de las influencias pedagógicas del extranjero y la búsqueda de nuevos métodos de aprendizaje de lectoescritura. Es la sección más corta del libro, pero a la vez es la más cercana a los intereses de las compiladoras.

En su texto Rodríguez Álvarez reconstruye los debates en torno a las estrategias de enseñanza de lectoescritura y la adaptación de modelos a la realidad de México. La autora realiza un recorrido histórico para señalar los diferentes métodos para enseñar a leer y a escribir, por ejemplo, el deletreo, el silabeo y el fonetismo, que "como sus nombres lo indican, el primero parte de la letra por su nombre, la "p" es "pe", la "x" es "equis" y así todo el alfabeto; el segundo del fonema (sílaba) y el tercero del sonido de la letra, sin enseñarse ya el nombre, la "p" es simplemente el sonido de la "ph". Para los dos primeros se utilizaron casi siempre tres instrumentos de enseñanza cuyo nombre comienza con la letra "c": cartillas, catones y catecismos" (Rodríguez, 2010, p. 310).

Por otra parte, Rodríguez Álvarez señala los cambios en los métodos cuyo efecto fue romper con el esquema tradicional de enseñanza memorístico de la lectoescritura, puesto que para la autora, dentro de su periodo de estudio, entre el inicio del México independiente y la Revolución mexicana, "se realizaron una serie de esfuerzos, búsquedas y cambios que lograron romper con la tradición de siglos de enseñanza rutinaria, memorística y opresiva; "la letra con sangre entra" fue la divisa a la que se enfrentaron los autores de los nuevos métodos, quienes buscaron hacer su conocimiento más efectivo y placentero (Rodríguez, 2010, p. 309).

La obra cierra con un texto de Montes de Oca sobre los contenidos de los libros de lectura y en particular ofrece un análisis del momento de su surgimiento en el periodo 19201940. La autora busca esclarecer el rol de los libros en las aulas escolares cuya importancia radica en que han sido, desde sus orígenes, instrumentos básicos para los procesos de enseñanza y aprendizaje de estudiantes y docentes en México. En la temporalidad escogida por Montes de Oca se busca contrastar los contenidos ideológicos de los libros de texto en un momento en que el régimen emanado de la revolución mexicana empieza a consolidar sus instituciones en un proceso no lineal que en el caso de la educación se vio reflejado en el experimento de la llamada 'educación socialista' que duró solo el sexenio cardenista, acorde con los tiempos de radicalización política que vivió el país.

Como últimas consideraciones habría que señalar que el currículo escolar, en el cual confluyen las disciplinas escolares, a la vez que conforma una manera de razonar en el mundo y del mundo, está dentro de una realidad históricamente determinada y determinante. Las disciplinas escolares son espacios de construcción social en donde se expresan los propósitos sociales de la formación escolarizada. 
Hay que señalar que en el libro colectivo se le da currículum escolar el rol de eje rector organizador, encargado de la selección y exclusión del contenido a transmitir, por medio de los textos. Los libros escolares o de texto son el medio de transmisión de esos conocimientos, el soporte material de los objetivos de enseñanza-aprendizaje. En ese sentido, explorar la historia de las disciplinas escolares es a la vez escribir la historia de los libros o textos escolares. Los autores se propusieron encontrar cuáles eran los "saberes" socialmente legitimados y aceptados, así como aquellas disciplinas con mayor jerarquía que permitían el proceso de culturización y finalmente, señalar cuáles de esos saberes han perdurado.

Por otra parte, aun cuando la mayoría de los autores se basaron en el análisis de libros o texto escolares, algunos autores usaron un uso extendido de la definición y emplearon otros tipos de objetos impresos. Ya que la noción de libro o texto escolar se ha ensanchado a través del tiempo y el análisis de fuentes de este libro es de sí mismo una prueba de esas transformaciones. Que, por otra parte, permiten al lector conocer el abanico de instrumentos empleados para alfabetizar, transmitir conocimientos, valores, actitudes, comportamientos, entre otros.

Uno de los fuertes de la compilación es la labor de contextualización de los autores, que sitúan las temporalidades en las que se crearon nuevas disciplinas escolares y nuevos tipos de libros. Muestran de manera holística y no dicotómica los cambios de métodos pedagógicos de enseñanza, así como las nuevas ediciones y los cambios de los textos. Lo anterior resulta de una organización de los contenidos por lecciones, tipo de actividades, imágenes, tipos de cuentos, cuadros, figuras, cuestionarios, entre otros. Otro de los aspectos a destacar, es que la compilación trata de mantener una secuencia lógica. En ese sentido, la división en tres segmentos es adecuada debido a que presentan el estudio de los textos y las disciplinas de acuerdo con una secuencia temporal. Sin embargo, hay una desproporción de las partes y una falta de inclusión de otras disciplinas como la educación artística, más allá del dibujo, la educación física y del deporte, la filosofía o la química.

Los autores cumplen sus objetivos de análisis uniéndolos a una explicación del porqué de la selección de las fuentes primarias. Finalmente, hubiese sido interesante conocer la distribución del tiempo de la jornada escolar dada a cada una de las disciplinas escolares las diferentes épocas, debido a que, si los autores se dispusieron a examinar las características pedagógicas, políticas e ideológicas de los textos y a dar a conocer cuáles materias estaban privilegiadas y cuáles no, el tiempo es un indicador que habría ayudado a comprender mejor este punto. 


\section{Referencias bibliográficas}

Galván Lafarga, Luz Elena y Lucía Martínez Moctezuma (coords.) (2010), Las disciplinas escolares y sus libros, Centro de Investigaciones y Estudios Superiores en Antropología Social/Universidad Autónoma del Estado de Morelos/Juan Pablos Editor, México. 